Article

\title{
Spiral Emotion Labor and Teacher Development Sustainability: A Longitudinal Case Study of Veteran College English Lecturers in China
}

\author{
Xiaowei Ding ${ }^{1, *}$, Peter I. De Costa ${ }^{2}$ and Guoxiu Tian ${ }^{3}$ \\ 1 School of Foreign Studies, Beijing Information Science and Technology University, Beijing 100192, China \\ 2 Department of Linguistics, Languages, and Cultures, Department of Teacher Education, \\ Michigan State University, East Lansing, MI 48824, USA; pdecosta@msu.edu \\ 3 College of Teacher Education, Capital Normal University, Beijing 100037, China; tgx37886@126.com \\ * Correspondence: dingxiaowei@bistu.edu.cn
}

check for updates

Citation: Ding, X.; De Costa, P.I.; Tian, G. Spiral Emotion Labor and Teacher Development Sustainability: A Longitudinal Case Study of Veteran College English Lecturers in China. Sustainability 2022, 14, 1455. https://doi.org/10.3390/ su14031455

Academic Editor:

Pedro Vega-Marcote

Received: 3 January 2022

Accepted: 24 January 2022

Published: 27 January 2022

Publisher's Note: MDPI stays neutral with regard to jurisdictional claims in published maps and institutional affiliations.

Copyright: (c) 2022 by the authors. Licensee MDPI, Basel, Switzerland. This article is an open access article distributed under the terms and conditions of the Creative Commons Attribution (CC BY) license (https:/ / creativecommons.org/licenses/by/ $4.0 /)$.

\begin{abstract}
Because the current literature on teachers' emotion labor (EL) mainly focuses on strategies and how EL correlates with relevant factors in the educational context, EL is generally treated as static and synchronic. The purpose of this study is to explore two veteran English lecturers' dynamic and diachronic EL development over the span of nearly two decades of their professional careers in China. Based on qualitative data that included multiple interviews, class observations, teacher reflective notes, student feedback, and institutional documents, the 18-month longitudinal study found that (1) veteran college English lecturers have mixed emotions and pervasive EL throughout their professional development experience, (2) the teachers' EL habitus has been shaped and reshaped by their life history in personal, relational, institutional, and sociohistorical contexts, and (3) their previous EL experiences have influenced their present EL practice, which in turn tends to predict their future EL preferences. In addition, our findings revealed that effective EL effort, especially in the form of actions combined with deep acting and genuine expression, is critical to the virtuous circle of EL and sustainable professional development of college English teachers. By contrast, ineffective EL effort, particularly the long-term surface acting of depressing negative emotions without eradicating the root causes or changing the unfavorable conditions, can impede the long-term sustainability of teacher development. Based on these findings, we conceptualize teachers' EL as a contextual and dynamic process that takes the form of spiral circles that teachers encounter throughout their professional life. These spiral circles, we add, can be virtuous or vicious in nature, and can thus either facilitate or undermine, respectively, the sustainability of their professional development. Research implications, limitations, and future directions are also discussed.
\end{abstract}

Keywords: emotion labor; sustainable teacher development; spiral circles; language teacher; higher education

\section{Introduction}

Educators have increasingly acknowledged that emotions not only constitute an indispensable part of teaching [1], but also serve as valuable resources for understanding teachers' professional lives [2]. Consequently, there is a consensus among teacher researchers that teacher emotions play an essential role in teaching and teacher development [2-23]. As a result, it is crucial for teachers to understand and manage their emotions in and through their professional praxis and development. That is, teaching, as an emotional practice [9], involves the intense emotion labor (EL) of teachers $[9,24,25]$, and is a topic that has drawn much investigative interest since the 1990s.

Unfortunately, most empirical studies in the current literature explore teachers' EL via the lens of strategies [26] such as surface acting (i.e., the expression of expected emotions by changing surface behaviors when one's feelings conflict with the feeling rules of the 
institution) [27] (p. 37), deep acting (i.e., the expression of expected emotions by coordinating one's deep feelings with the institutional feeling rules) [27] (p. 38), or the expression of genuine emotions [28]. In particular, based on large-sampled questionnaire surveys or scale measurements, these quantitative studies mainly aim at describing, categorizing, and generalizing the EL strategies of teachers in a certain region or in a certain phase of education [29], as well as analyzing the correlation between different EL strategies and other variables in teachers' professional life, such as self-efficacy, burnout, commitment, etc. $[18,23,25,30,31]$. In other words, such synchronic research treats teachers' EL as a static status quo of certain groups of teachers and frames EL largely as strategies that are deployed in general at a certain point of time. Such an approach often does not take into consideration the fact that teacher emotions are constantly shaped and reshaped by historical, cultural, and political contexts, and are thus fluid and dynamic in nature [32]. Our current work thus seeks to fill this research gap by exploring two veteran English lecturers' dynamic and diachronic EL development over the span of nearly two decades of professional development in China.

The significance of this longitudinal case study is twofold. First, in terms of terminology, we seek to clarify teachers' EL as a (re)shaped and evolving process that entails long-term negotiation between teachers and their social contexts in the form of their changing emotions and changing emotional rules. In taking this stance, we problematize a static understanding of EL that conceptualizes this concept solely in terms of labeled strategies. Second, our goal is to explore the complex interactions between teachers' EL and the sustainability of their professional development; in particular, we aim to investigate how teachers' professional development affects their EL, and how incongruent EL experiences result in sustainable or unsustainable teacher development.

In the remainder of this paper, we review key terms and the current state of research related to this study in more detail, before moving on to provide a brief description of our research aims and principal conclusions. Sections 2 and 3 provide a transparent illustration of our research design and major findings; we then go on to interpret and theorize our findings in Section 4. Finally, the implications and limitations of the current study, as well as future research directions, are discussed at the end of this paper.

\subsection{Key Terms}

The term "emotion" is traditionally regarded as the result of the changes of physiological systems [33] or psychological appraisals based on individual objectives and well-being [34], involving physiological stimuli and responses, psychological cognition, and behavioral disposition and manifestation [35]. However, it is increasingly viewed as a socially constructed concept whose connotation and expression are defined by cultural ideology, beliefs, norms, rituals, and social structures [36]. A case in point is teacher emotions, which are the "complex, multifaceted experiences that arise in a variety of sociopolitical relations and contexts" [37] (p. xviii). In other words, teacher emotions are constructed through their interactions with students, colleagues, administrators, and other parties in their respective pedagogical, institutional, and sociohistorical contexts. Because teacher emotions are pervasive in the professional practice of teachers [38] and central to teaching [12,39], it is critical for teachers to manage emotions in their professional life by engaging in emotion labor. The term "emotion labor" was first proposed as "emotional labor" by Arlie Hochschild, who defined it as the emotional management in workplace to "induce or suppress feelings in order to sustain the outward countenance that produces the proper state of mind in others" [27] (p. 7). Because this type of labor, in addition to physical and mental labor, has exchange value, it can be traded in for a wage [40].

Admittedly, some teacher researchers prefer the word "emotion" to "emotional" so as to avoid the negative association of the latter in its meanings. Instead they have argued that teachers' EL is actually a healthy response to challenging conditions in teaching, and an active negotiation or struggle that purposefully seeks agreement among their educational beliefs, professional training, and explicit or implicit emotional rules [39,41]. In addition, 
the exchange value of teachers' EL is expanded from merely monetary rewards (e.g., a wage or a salary) to emotional ones (e.g., sense of achievement, social praise, job satisfaction, etc.), which transforms teachers' EL into a double-edged sword [42]: on the one hand, it reveals that teachers are restrained or even oppressed by the emotional rules in the cultural, social, or institutional contexts, so that they are qualified to meet the emotional demands of their profession; on the other hand, it legitimizes teachers' pursuit of emotional rewards, which provides them with a continual driving force in their pursuit of sustainable professional development.

\subsection{Current State of Teachers' EL Research}

Influenced by the large-scaled, large-sampled quantitative research approach that has dominated the empirical research related to EL, studies on teachers' EL have also adopted questionnaire survey or scale measurement as a dominant research method, and this tendency has extended to recent work [43]. A case in point is the three large-scaled surveys among secondary school teachers in Croatia conducted by Buri'c, Penezi'c and Sori'c [29]. Based on the process model of emotion regulation [44,45], they generalized and categorized teachers' EL strategies as avoiding situations, active modification, reappraisal, suppression, and tension reduction. Another instance is that, based on a localized Teacher EL Strategy Scale [46], Yin, Huang and Lee [25] surveyed 1115 primary school teachers in Hong Kong, and concluded that the EL strategy of surface acting significantly negatively correlated with teacher efficacy, while strategies of deep acting and expression of genuine emotions tend to promote teacher efficacy. In a related study, Zheng, Yin, and Wang [47] analyzed the relationships between leadership practices, emotional labor strategies, and teacher efficacy by collecting quantitative data from a questionnaire survey that was administered to 1026 primary and secondary school teachers in China. Their principal findings were not only consistent with those of the previous study, but these findings also reinforced the important role of EL strategies in leadership practice; that is, surface acting and a genuine display of emotions significantly mediate the effects of leadership practices on teacher efficacy beliefs. Overall, the majority of these studies analyzed the correlation between these strategies and other variables in teachers' professional development in addition to describing and categorizing the EL strategies adopted by teachers who work with learners across different age groups (e.g., kindergarten, primary school, university, etc.).

However, such quantitative and descriptive studies are less likely to reveal the contextuality and complexities that underpin teacher EL. To this end, researchers have also explored this popular theme via qualitative and interpretive means. For example, in light of the Confucian culture in China, Yin [21] interviewed 8 high school teachers, and generalized 7 localized strategies (pretending and restraining, which belong to surface acting; refocusing, reframing and separating, which are categorized as deep acting; releasing and outpouring, which are used by teachers to express genuine emotions to their students) that are commonly utilized in classroom teaching. However, most descriptive or interpretive studies still regard teachers' EL strategies as a static entity that is related to emotional manipulation and management, or teacher EL.

By contrast, in this paper we argue that teacher EL should be treated as a dynamic process in accordance with teachers' professional development. Our proposal is in fact inspired by several researchers who have underlined the significance of teachers' dynamic EL based on "longitudinal studies ... (that) will help determine how teachers develop their emotional regulation ... strategies" [48] (p. 395). One of the earliest influential longitudinal studies on teachers' emotions and EL is Zembylas's [32,37] work. He conducted a 3-year case study about a primary school teacher, Catherine, and explored her emotional experiences when she taught science in different stages of her professional life. By proposing a longitudinal approach that involved "genealogies of emotions in teaching" [37] (p. 97), which he describes as "a process of finding out the historicity of emotional experiences" that "casts light on how emotions are located and represented in teachers" 
work and personal/professional development" [37] (p. 98), Zembylas traced the trajectories of Catherine's emotional experiences and analyzed her EL changes in an implicit manner.

Recently, more researchers have turned their investigative gaze to the temporal dimension of teacher emotions and EL strategies. As for qualitative studies, Taylor, Newberry, and Clark [49] analyzed the 14-week emotional episodes of the first author who recorded and discussed these episodes with a critical friend. They found out that as she gradually recognized and contextualized her surface emotions, she gained a greater understanding of herself and her deeper emotions, which in turn enabled a more effective practice of emotion regulation and reduced the level of her negative emotions. In another study, Gao and Cui [50] conducted a longitudinal case study about a team leader and a team member of an English for academic purposes (EAP) teaching team during an institutional curriculum reform in a Chinese university. Based on six rounds of interviews over two and half years, they tracked their EL changes and found that both of the team leader and team member applied the EL strategy of genuine expression most frequently, and deep acting least frequently; but due to their different identities and team roles, the team leader experienced increasingly intense and frequent EL, while the team member's EL tended to decrease in intensity and frequency.

At the same time, however, a few quantitative studies have also started to investigate the progression of teachers' emotional experiences and regulation in their professional life. For instance, Lavy and Eshet [51] investigated the daily dynamics of emotional experiences of 62 teachers, who completed daily measures of their own emotions, emotion regulation, burnout, and job satisfaction during a span of 10 workdays. The authors also confirmed the linking of teachers' emotions and their EL strategies, namely the negative spiral effects of teachers' negative emotions and surface acting, as well as the positive spiral of their positive emotions and decreased surface acting. In addition, the results of their study highlighted the obvious impacts of both negative and positive spirals on teachers' burnout and job satisfaction in their professional development.

In order to supplement longitudinal qualitative research in the current literature, this study aims to explore the trajectory of two veteran college English lecturers' EL following nearly two decades of their professional development in China. Our study was guided by these two questions:

1. What EL changes do veteran college English lecturers experience at different stages of their professional life?

2. How do the changes of EL impact the sustainability of teacher development?

Based on a series of qualitative semi-structured interviews, class observations, teacher reflective notes, student feedback, and institutional document collection over 18 months, our findings revealed a complicated spiral interaction between their different EL habitus and disparate sustainability of teacher development.

\section{Methodology}

This study adopted a longitudinal, qualitative case study approach. Because longitudinal case study research tends to be more explorative and interpretive in nature, it is well suited for better understanding a complex phenomenon in a natural setting, such as teachers' EL, particularly for a deeper exploration of the change or process of the phenomenon [52]. Therefore, a longitudinal qualitative research method is more appropriate when investigating teachers' EL, the research focus of our study, which is a complex and changing social phenomenon. In addition, as to teachers' emotions and EL strategies, it is more likely that the participant teachers will provide a detailed and an authentic description of and comments on their emotional experiences, especially when they have established a mutually trustful relationship with the researchers and are willing to open up to the latter [6]. In fact, such a case study approach is also a well-established research method in the published EL literature $[10,27,37,39,41]$. 


\subsection{Setting and Participants}

College English is a compulsory course for all non-English major freshmen and/or sophomores in Chinese universities, and its position in the curriculum system of higher education in China varies according to the national language policies and educational reforms. From the late 1970s to the first few years of this century, it was positioned as a major compulsory course from primary schools to universities, and the college English Test band 4 (CET-4) certificate was mandatory for undergraduates to obtain their diploma. As a result, college English courses were also highly valued by non-English majors who were strongly motivated to work hard to meet the rigid graduation requirements. However, since 2005, CETs have no longer been high-stake examinations for most students in Chinese universities, and the latest national language policies in China have placed even less emphasis on English. Consequently, college English has been positioned merely as a basic course in higher education, in which college English teachers have to invest increasingly more time in arousing students' interests in English and managing student misbehavior in class. This change in the status of college English courses and students' motivation has generated emotion labor among college English teachers.

What is worse, the late 1990s and the first decade of this century brought two major reforms in Chinese higher education which profoundly influenced college English teachers. One was the enrollment expansion movement of universities in China, which raised the gross enrollment rate of higher education from merely $2-3 \%$ in the early 1980 s to as high as $34.5 \%$ in 2013, and elevated the acceptance rate from $34 \%$ in 1998 to $75 \%$ in 2012 . This means that college English teachers who are responsible for teaching all non-English students have to take on an expanded workload, while having to work with students with increasingly lower college entrance examination scores, as well as progressively lower English proficiency. Hence, it is understandable that the double, even triple, workload and obvious erosion of students' English skills have placed more pressure on college English teachers, resulting in more EL in their increasingly challenging teaching [43].

The other reform was the assessment system based on accountability of teachers for the purpose of university ranking and teacher performance evaluation. For college English teachers, one of the major indicators of accountability is the passing rate of CET- 4 and CET-6, which has resulted in the college English course becoming a test-oriented training project and, correspondingly, constructs college English teachers as representatives of an examination drill culture. These realities have hampered the professional growth of college English teachers, which in turn has impacted their emotional experiences. Veteran college English lecturers, in particular, are more likely to experience striking EL changes and, thus, become the subject of investigation in our study that explores two focal teachers' EL trajectory and its interaction with sustainable teacher development.

Three selection principles were taken into consideration when identifying our two focal teacher participants. The first one was the adoption of a 'no strangers as participants' stance. Due to the sensitive characteristics of emotions, it would take too long a time to establish research relationships of mutual trust, so that true feelings and thoughts of the participants could be revealed and shared. The second principle embodied a 'no intimate friends as participants' stance because of the potential ethical risks. On the one hand, friendship with the first author, who was responsible for data collection and initial analysis, may distract her attention to negative but critical details, resulting in conclusions more favorable to participants. On the other hand, her friends may go out of their way to help her by guessing her research purpose, and thus deliberately shape their narratives of emotional experiences. The last principle was that of 'feasibility'. The first author, who is located in Beijing, China, is a full-time educator and researcher, with a teaching workload of 12 credit hours per week. Hence, she could not afford the time to investigate participants out of town in order to guarantee the frequency and duration of observations and interviews. Therefore, in keeping with purposive sampling principle [53], she contacted a dozen veteran college English lecturers in different universities in Beijing, who attended the same in-service training programs as she did so that she was an acquaintance but not a close friend of 
theirs. Eventually, she successfully collected qualitative data from four of them, among whom Mr. M. and Ms. H. (our focal participants) reflected more typical EL experiences and professional development.

The School of Foreign Languages where Mr. M. worked is a marginalized school within his university, and college English teachers are further marginalized because the basic course they teach has been regarded as less academic than specialized courses. Since there is a tradition that male teachers should take on a bigger workload than their female colleagues, he was forced to teach about $400 \mathrm{~h}$ a year most of the time during his 18-year career, which came up to two to four times the workload of teachers of specialist subjects. However, Mr. M. had to complete the same research tasks as his specialist teacher colleagues including engaging in publications, research projects, and thesis tutoring, in order to compete with his counterparts for promotion. He was so fed up with all the disappointments in his professional life that he quit his job shortly after our study ended.

By contrast, Ms. H. teaches in a small university which emphasizes the need to cultivate bilingual professionals. Ms. H. usually takes on a workload of nearly $400 \mathrm{~h}$ a year, including compulsory and elective English courses, but she always works hard to establish an interactive class atmosphere and to maintain a mutually respectful relationship with her students. As a result, she is a popular teacher among her students and a core member in the team of English teachers. By the end of our study, she had won several prizes in teaching contests of different levels and was confidently planning to pursue more professional goals.

\subsection{Data Collection}

The first author was responsible for data collection. She contacted only one potential participant teacher at each university at the outset of this study to avoid any possible conflict of interest with other colleagues or their supervisors. She informed the participant teachers of the research purpose, participant rights, and researcher obligations in the written consent via WeChat messages and emails. She also reminded the participant teachers of the research ethical principles before the first two interviews, class observations, and teacher reflection collection, to reduce possible anxiety or concern in the hope that they would make honest comments on their emotional experiences.

Since the first author (Ding) was also a veteran college English teacher herself and because she was acquainted with Mr. M. and Ms. H. before the current study, they shared many topics in common during the pre-study communication. Thus, the relatively trustful relationship between Ding and the participant teachers was established not long after the study began, which resulted in gradually longer and more informative interviews taking place. In order to obtain more contextual information for data analysis later, Ding observed the participants not only in class, but also in the teachers' lounge, the campus store, the hallway, and other relevant sites of their professional life. She then wrote researcher field notes immediately after she returned from her fieldwork.

Additionally, by attentively listening to the participant teachers and expanding her follow-up questions, she enquired about their personal lives outside of school. Such background information drawn from various social contexts provided more depth and understanding to their emotional experiences. Ding also chose similar class events she observed during different class visits as the basis of lead-in questions for different interviews that she staggered over the duration of this longitudinal study (see Appendix A). She did this in order to (1) double check the coherence of the thoughts and comments of participant teachers, and (2) track subtle changes in their EL. Usually, it was Ding who proactively arranged for the next meeting of observation or interview, but sometimes the participant teachers would also take the initiative to invite Ding to their class. At the end of their interviews, Mr. M. and Ms. H. would enquire about Ding's research, work, and family, and in turn she would present a gift or thank-you card to express her gratitude for their selflessly investing so much time and efforts in the research project. As a consequence, both teacher participants opened themselves up to provide abundant information and vivid stories about their professional life. 
During the interviews, Ms. H. laughed a lot and often gratefully sighed, "Oh time flies, I have been talking and talking for so long time. Thank you so much for listening to me and helping me do such a fruitful reflection". That is why Ms. H. was interviewed fewer times but for a longer duration and had more words in her interview transcripts (see Table 1). By contrast, Mr. M. was deeply disappointed and extremely passive towards his students, his teaching, the college English course, and higher education in general when he agreed to be our focal teacher. Because he was doubtful of any efforts to improve college English teaching and teacher development, suspicious of research (see Section 3.2), and because teacher-student relationship became increasingly distant (see Section 3.3), Mr. M failed (twice) to collect student feedback in class. He also refused to write any reflective notes after his interviews were done, because at that time he had already quit his job, and swore never to look back at his teaching profession. The two " 0 " records in Table 1 were indicative of his ineffective EL and unsustainable professional development as a college English teacher.

Table 1. Data collection information.

\begin{tabular}{ccc}
\hline Participant Teacher & Mr. $\mathbf{M}$ & Ms. H \\
\hline Interview (times/minutes) & $6 / 229$ & $4 / 241$ \\
\hline $\begin{array}{c}\text { Class observation } \\
\text { (times/minutes) }\end{array}$ & $4 / 200$ & $4 / 200$ \\
\hline $\begin{array}{c}\text { Interview transcript } \\
\text { (thousand characters) }\end{array}$ & 62.3 & 64.2 \\
\hline $\begin{array}{c}\text { Adjusted interview transcript } \\
\text { (thousand characters) }\end{array}$ & 52.6 & 63.8 \\
\hline $\begin{array}{c}\text { Reflective notes (characters) } \\
\text { Student comments (Chinese } \\
\text { characters) }\end{array}$ & 0 & 3129 \\
\hline Other data & $\begin{array}{l}\text { WeChat and phone messages, } \\
\text { emails, university documents }\end{array}$ & $\begin{array}{l}\text { WeChat and phone messages, } \\
\text { emails, university documents }\end{array}$ \\
\hline
\end{tabular}

Although Ding earned the trust of and cooperation of our participant teachers thanks to her insider identity, we remain cognizant of the possible impact of her own professional history, theoretical disposition, and qualitative research experience on the construction of the research relationship, as well as on the data collection and analysis processes.

\subsection{Data Analysis}

We analyzed our research data in five steps, among which the first author, Ding, was responsible for the most time-consuming first three steps; all three authors went through the remaining two steps through rounds of negotiation and editing, however. Specifically, during the first step, Ding transcribed interview recordings, and re-read interview transcripts, observation notes, Ms. H.'s reflective notes and her students' comments, and relevant university documents. She did this to gain a more comprehensive picture of the data corpus. Then with reference to the research questions, she conducted the encoding of transcripts in the second step. Following the encoding of categories of context, opinion, interpretation, process, activity, event, and strategy [54], she initially identified more than 50 themes that emerged from the data. After applying these themes to other data sources, she eventually merged the themes into 20. In the third step, she categorized the 20 themes into 6 groups on 4 levels (see Table 2). 
Table 2. Twenty themes, six categories, and relationships on four levels.

\begin{tabular}{ccc}
\hline Themes & Categories & Relationships \\
\hline $\begin{array}{c}\text { Reason for being teacher, Individual, } \\
\text { Family }\end{array}$ & Background & Personal \\
$\begin{array}{c}\text { Beginning of career, Teaching practice, } \\
\begin{array}{c}\text { Teaching conception, Research, Teacher } \\
\text { identity, Professional identity }\end{array}\end{array}$ & Professional development & \\
\hline $\begin{array}{c}\text { Students, Teacher-student relationship, } \\
\text { Teacher-student interaction }\end{array}$ & Students & Interpersonal \\
\hline $\begin{array}{c}\text { Direct leader, Colleague relationship, } \\
\text { Colleague interaction }\end{array}$ & Colleagues & \\
\hline Policies, Reforms & Institution & Institutional \\
\hline Education, Times, Culture & Context & Societal \\
\hline
\end{tabular}

At the fourth step, Ding drafted the narratives of Mr. M. and Ms. H. based on the above themes, categories, and relationships, by selecting typical excerpts from research data. The other two authors, De Costa and Tian, consulted with her about the validity and logic of contextualized in-case analysis, and helped with the editing and wording of this manuscript when necessary. Ding also invited the participant teachers to check the initial draft of their narratives and she also revised the draft according to their feedback.

At the last step, we negotiated and decided on the similarities and differences of participant teachers' individualized EL changes, and the disparate spiral effects between their EL and professional development, so as to answer the research questions and to draw conclusions through the cross-case analysis. We undertook the abovementioned measures of data collection and analysis to examine and improve the validity and reliability of our research data, which laid a solid foundation for our findings to which we turn next.

\section{Results}

Our findings corroborated with the observation that teacher EL constitutes "ways in which they (teachers) negotiate tension ... between feeling rules and teachers' professional training and/or experience" [39] (p. 1). In other words, teacher EL entails "the emotion regulation efforts that teachers [make to] negotiate the conflicts among emotion rules, educational conceptions, and their professional practice when they interact with students, colleagues, and the institution" [43] (p. 24). Based on this understanding, we decided to present the major findings of our research in terms of Mr. M. and Ms. H's narratives on different stages of their professional life. In particular, we found that their EL trajectory took the form of spiral circles, and we will demonstrate its relationship with the sustainability of their professional development.

\subsection{Teacher EL at the Starting Line: Managing Anxiety and Uneasiness}

Both teacher participants disclosed that their EL experiences could be traced back as early as the first class when they stepped up to the lectern in the classroom for the first time. A key part of their EL entailed dealing with anxiety that stemmed from the uncertainty about the new career, and from the uneasy adjustment or adaptation to the role of being a language teaching professional.

Mr. M. still remembered his uneasiness and lack of confidence in the early days of his teaching, because he just obtained his bachelor's degree and was not sure whether his spoken, accented English could "hold the class" (Interview-M-1) where his students were only two to three years younger than him. Anxious young college English teachers like Mr. M. were not rare around the end of 1990s, since China's opening-up policy and prosperous international trading encouraged most English majors to study abroad. At that time, many English teachers resigned and started working in foreign companies, resulting in a lack of English teachers at universities. He kept saying that becoming an 
English teacher was "a joke of destiny" (Interview-M-1) because he was weak at English and had never planned to be a teacher upon his graduation. With little passion for English education, Mr. M. quit one university as a student, without having learned any educational theories, and joined another as an English teacher with literally no teaching experience. Consequently, he had no idea what kind of teacher he would become; nor was he aware of how to teach effectively based on students' demands and English proficiency. He then spent most of his spare time in the library, reading educational books and preparing and revising his lessons. Gradually, he found some confidence when facing his peer-like students as "an authority" (Interview-M-1) in his class, even though he did not see teaching as a desirable career. In this way, he managed to overcome his lack of confidence and anxiety through EL by making up for his limited ability to negotiate the difference between the emotion rules of teachers (e.g., confidence, commitment, etc.), his educational conception of teachers as authorities, and his inexperience in teaching practice.

Ms. H. also suffered from anxiety and uneasiness at the beginning of her professional life, even though she started her career of teaching with a master's degree, and had accumulated experience of teaching English by tutoring pupils and teaching part-time at language training institutes when she was an English major. However, she was still diffident about her limited knowledge of educational theories because she did not graduate from a normal (i.e., teaching) university (just like Mr. M.). She was also uncertain whether the imbalance between her theoretical and practical knowledge of English education would undermine her professional development (Interview-H-1). As a result, Ms. H. tried hard to optimize every opportunity of in-service training at home or abroad, and eventually became a confident and passionate teacher with both adequate theoretical knowledge and practical English teaching experience. In short, like Mr. M., she also managed her negative emotions as a novice college English teacher through EL by working on her shortcomings.

In particular, we found that both teachers' EL was profoundly impacted by their early teaching career experiences and coming to terms with the role and responsibility of college English teachers in higher education. Specifically, their teacher EL was shaped by their beliefs of "good teaching of English" (Interview-M-1), which in turn was based on their own English learning experiences, pre-service education, or in-service training upon entrance. Mr. M. learned English at high school by purely memorizing words and grammatical rules, and mainly taught himself English at college (with some guidance from his professors), especially with regard to improving his English listening and speaking skills. That was why Mr. M. believed throughout his professional life that language is defined by lexical and grammatical rules, and that the most effective and efficient English teaching was based on the autonomous learning of students, with targeted guidance from the teacher:

College English is a special subject, in which, I believe ... students are expected to enlarge their vocabulary by themselves, then grammar, then practice their own reading, writing, and speaking, through a stage of autonomous learning. No sense for us to lecture in class.... Generally speaking, the ideal status is that students learn English by teaching themselves, rather than being taught in class, and teachers are responsible for answering their questions, organizing the class, assessing their learning, and pointing out the right direction for them. That's the most valuable teaching. (Interview-M-1)

In other words, he believed that his basic responsibility was to urge students to develop their vocabulary and to memorize rules of English usage in order to improve their English skills; in the meantime, he just waited for students to come to him for help and guidance (Interview-M-1). Thus, his early EL strategies were mainly genuine expressions of felt emotions, such as expressing disappointment and discontent to his entire class, when students did not meet his requirements regarding self-teaching and autonomous learning.

As for Ms. H., teaching English at university was always her dream job, and she credited the realization of her professional dream to her "four years of hard work as an undergraduate in a second-class university who earned a master's degree in a first-class 
university" (Interview-H-1). In addition, she described English as being "one more window in a room for you to appreciate the outside scenery from a different perspective"; such as perspective also strengthened her infinite belief in her responsibility as a college English teacher which she saw as "raising the English proficiency, broadening the horizon, and deepening the worldview" of her students and helping them "achieve leaping growth" (Interview-H-3). That was why Ms. H. took English teaching seriously and saw her need to "set fire to students' passion" and to facilitate their growth "through the medium of English" (Interview-H-1). Thus, her original EL strategies were combined. When she faced unfamiliar students in a new class, she would pretend to be exaggeratedly enthusiastic via surface acting, in order to hide her "introverted disposition" and to restrain her disappointment and anxiety "if new students gave no responses in class" (Reflection-H-2).

In addition, when facing students' progress in English study, ethical qualities or critical thinking in class performance, or even certain personal achievements, she would exude her happiness and pride directly via the strategy of genuine expression by openly commenting and praising them in front of the class (Class-observation-H-4). As to students who had difficulty in English learning, or those who misbehaved in her class, she would invite them to have a heart-to-heart talk after class to work out their problems and to offer thoughtful suggestions and warm encouragement (Class-observation-H-2). In this case, her EL strategy was basically deep acting in nature, as reflected in her disclosure:

I have also been meeting extremely introverted or rebelling students ... Surely, I would always feel a bit disappointed or upset, in the bottom of my heart, but I would also make a quick adjustment ... because there must be some reasons for their ... psychological wall or fence ... Don't take it personally since it's for sure that they are not aimed at you. The possible involving factors may be quite complicated ... So the first step is a placid and patient attitude. Even when students lose their mind, we teachers should always stay rational ... I don't criticize them directly, rather, I frequently talk to them, pay attention to them, and ask them questions, so they know they are taken seriously and not forgotten ... I definitely feel their trust in me, to certain extent, and they feel that my class is worth their attention, too ... In addition, I never give up ... and do as much as possible within my capability, that is, to plant seeds [in their heart]. (Interview-H-2)

In other words, $\mathrm{Ms} \mathrm{H}$. tended to keep calm and patient by eliminating her disappointment, while arousing hopefulness and trust in her students through self-encouragement, psychological reappraisal, and active responses.

Both Mr. M. and Ms. H. continued to rely on their specific EL strategies based on their initial negotiation of emotion rules, educational conception, and their teaching style at this first stage of their professional life, until turning points in their teacher development brought changes to their pedagogical conception or practice.

\subsection{Teacher EL at the Turning Point: Managing Fear and Surprise}

The turning points in teachers' professional development usually emerge during educational reforms and major changes to educational policies, which either gradually change teachers' educational conceptions, or transform their professional practice.

As for Mr. M., the early 2000s (i.e., the turn of the century) brought a college-merging reform in higher education, resulting in new administrative policies which urged teachers with only a bachelor's degree, like Mr. M., "to pursue higher degrees, otherwise they would be banned to teach" (Interview-M-4). To eliminate the fear of losing his job once and for all, Mr. M. decided to take action, a form of EL that he increasingly relied less on, to manage his panic: he left his beloved wife and baby daughter for 10 months until he successfully obtained his master's degree in Teaching English to Speakers of Other Languages (TESOL). This time, he was confident that the "gilded certificate" (Interview-M-4) would bring opportunities for his professional development. Unfortunately, his direct superior valued neither his efforts to meet the demands of new policies nor his higher degree, and he was 
assigned even more Class Bs, whose students were less proficient in English than those in Class As, to make up the required workload during his 10-month absence.

Unfortunately, Mr. M.'s newly earned master's degree did not translate into "any new opportunities or resources in title promotion, performance awards, research funding, or inservice training" (Interview-M-4). What was worse, his overseas study experience further reinforced his educational conception, from a theoretical perspective, that fostering learner autonomy was more critical to English teaching than lecturing by teachers. However, his teaching moved even further away from his ideal because of the lower English proficiency and weaker motivation in learning English of his students due to the enrollment expansion movement in higher education (see Section 2.1). Gradually, he started to conceal his disappointment and dissatisfaction by pretending to "be indifferent to students who were mostly opportunistic, lazy, and afraid of pains" (Interview-M-6). Lastly, his overseas study also intensified his pessimism regarding English teachers' academic research. Because of his hurried MA thesis at the end of the 10-month study abroad, he became skeptical of academic research and saw writing journal papers as "an extensive and cunning copying from others" (Interview-M-6), a view that further weakened his motivation to conduct academic research. As a consequence, Mr. M. found himself in a more marginalized and disadvantageous position in the academic promotion system.

A vicious circle subsequently emerged: the widening gap between his pedagogical conceptions and the unfavorable conditions of his teaching and depressed professional advancement made it harder for Mr. M. to feel and express desirable emotions (e.g., passion, enthusiasm, commitment) or feeling rules [55,56] that were expected of educators. In other words, he found himself in a downward spiral: the less effective his EL was, the more negative emotions (e.g., anger, dissatisfaction, and hopelessness) Mr. M. felt towards his professional development. After the turning point of his aforementioned job crisis, the more inclined he was to withdraw and escape in the face of repetitive failures and mounting frustration with teaching, research funding applications, and publishing papers in academic journals. In addition, the less effective his EL became, the wider the gap became between his reinforced educational conception and his students' performance, which resulted in a professional development bottleneck. Therefore, instead of mobilizing his original EL strategy of genuine expression, Mr. M. started to perform surface acting by pretending to be indifferent to the misbehavior of his students and the obstacles in his career; he even relegated his work to "just a bread-earning job that is not as sacred as originally imagined" (Interview-M-1).

Ms. H. also suffered from a career crisis as the turning point of her professional development when her university followed the national language policy and enacted a curriculum reform:

The position of college English course in the curriculum system was lowered, so the course was shortened from 4 semesters to 2, with its class hours cut in half ... My university also carried out an institutional reform by redividing each school to optimize the design of students' majors, resulting in a shrink [ing] of [the] student body at my school ... With less class and students, ridiculously, the total amount of our workload that was required by the annual teacher performance evaluation remained the same ... What was worse, we are not allowed to offset our shortage of teaching hours with journal papers ... They just told us to figure out a way by ourselves to make up the gap of our workload, otherwise we would be deprived of our teaching position. (Interview-H-3)

Similar to Mr. M., the fear of losing her job also drove Ms. H. to take action, a form of EL that she frequently performed. For example, to deal with her desperate emotion, she applied to teach some elective courses, even though she had to manage her anxiety of preparing for the new courses within a limited time. Unfortunately, due to the limited classrooms available, her applications were not approved. So for a while, the mixed emotions of anger and helplessness demoralized her, but thanks to her educational (and professional) conception of always believing in perseverance and hope in change, growth, 
and development, as well as the constructive effects of her EL to establish a trustful relationship with her students and to solve problems in her teaching, Ms. H. decided to take action again. Specifically, she turned to her favorite form of EL, which was "to appeal to the administrators together with some other colleagues who were facing the similar dilemma of professional development" (Interview-H-3). This time, Ms. H. relied mainly on the strategy of genuine expression: she exhibited her fear and anxiety by honestly describing "the torturing situation" that college English teachers like her were stuck in, and by frankly arguing against "the potential disadvantages of radical reforms at one time" (Interview-H-3). Finally, her university agreed to add one more semester of college English course, which temporarily resolved her career crisis. This time, her EL of genuine expression based on collective efforts worked.

After her successful negotiation with the administrators, Ms. H. did not wait for more favorable policies of her university to emerge, because she was aware of "the tendency of the nationwide curriculum reforms", and that one more semester of college English only bought her "limited time to adapt to the irreversible trend of class hour reduction of college English" (Interview-H-3). This deep acting strategy of EL helped her actively seek opportunities to teach English courses other than college English, such as EAP courses for English majors, and cultural elective courses. Before long, she met the requirement of teaching hours for teaching evaluation, eliminated her fear of losing her job at this turning point, and regained her confidence in professional development through her constructive EL experiences.

In short, both Mr. M. and Ms. H. encountered a similar crisis of losing their job as a turning point in their professional development, and both performed EL in the form of purposeful actions to manage their fear and surprise. However, the different effects of their EL efforts led them to solidify or transform their EL habitus, resulting in their gradually growing into different types of veteran college English teachers.

\subsection{Teacher EL at the Veteran Stage: Managing Hopelessness and Hopefulness}

With the passage of time, neither Mr. M. nor Ms. H. was promoted in terms of professional title, and during the veteran-lecturer stage of their career, Chinese universities generally carried out more institutional reforms. For example, teachers' salary was linked to their professional title instead of their workload; university faculty were deprived of their iron rice bowl (i.e., a secure job) and had to sign an employment contract every 3 or 4 years based on the teacher performance evaluation, which set increasingly higher requirements for teaching and academic research. One policy remained unchanged: the core indicator of the teacher accountability system for college English teachers, which mainly involved raising the student pass rates for CET-4 or CET-6.

Such exam-oriented teaching was actually consistent with Mr. M.'s own English learning experiences and his educational emphasis on vocabulary building and grammar drilling. However, due to the disconnect between CET- 4 and the requirements for a bachelor's degree of college students (see Section 2.1), most of his Class B students were barely motivated "to drill CET items before class" as he required, and "seldom provided responses to his lecture in class" (Class-observation-M-3). The sharp contrast between his English-education conception and teaching reality continued to irritate him and subsequently required more EL effort on his part, because he still pretended to be indifferently calm in class even when "a third of [his] class was absent" and the rest of the class was "too noisily misbehaving to carry out the teaching plan" (Interview-M-6). By "keeping one eye open and another closed in class" (Interview-M-5), his EL seemed to further worsen his teaching effects, resulting in a distant teacher-student relationship. In other words, his surface acting of indifference not only failed to solve pedagogical problems, but also intensified his helplessness and resentment towards his students and exam-oriented teaching:

The students can deal with you with 10,000 methods ... Some are late, others are browsing their smartphone, and no one is listening to you. Then your heart is chilled ... Teaching such a class is really torturing. (Interview-M-5) 
I'm not angry [sighing, silence]. They seem to listen to you, so what? You don't know whether their mind is here or not ... Sometimes I also pointed out [their misbehavior], but with no responses, you got annoyed, and they got annoyed, too. (Interview-M-1)

It's like you can force the cattle to the river but can't force them to drink. (Interview-M-3)

They are like coming to a picnic, eating, drinking, playing, chatting while you are talking. It's just useless to encourage, to criticize, or to punish them. It's a class that I can do nothing to help ... I can't do anything about it, and it's absolutely frustrating ... I hate such intensive training of exam items even more than the students do. (Interview-M-6)

Mr. M. felt hopeless not only about his teaching, but also became disillusioned about his professional development. New policies of high-level research funding application limited applicants to lecturers under 35 or with a Ph.D. degree, or exclusively to associate professors and professors. Mr. M. felt humiliated not only when facing such discrimination associated with age, degree requirements, and professional title, but also when submitting his manuscripts to prestigious academic journals in China, because he had to tick 'No' in the author information table, which privileged others such as those who were professors who tutored Ph.D. students, or were engaged in provincial or national research projects. He also tried submitting his research to general-level journals, but after rounds of rejection or non-response, he felt even more humiliation, hopelessness, and helplessness. In the end, he felt liberated and decided to give up his pursuit of professional title promotion for good. By this time, Mr. M.'s feigned indifference via surface acting strategy could no longer mask his fake calmness and temporary psychological balance; and he found it increasingly hard to conceal his bitterness and disappointments in his professional life. He disclosed: "Don't count the days, otherwise it's even more unbearable". (Interview-M-6). That was why he refused to write reflections on his teaching half a year after his last interview, because he had already resigned by then, and preferred not to look back on those painful days any more.

As for Ms. H., the exam-oriented English teaching style ran counter to her educational conception which emphasized English learners' "all-round quality and whole-person growth" (Interview-H-1). Fortunately, her "consistent enthusiasm" and "perseverance towards English teaching" (Student-feedback-H) had earned the trust and appreciation of her direct superior, who often assigned her to teach the advanced experimental classes of EAP and classes with top students where it was relatively less necessary for her to manage the class all the time. Teaching these motivated students with higher English proficiency, she was still able to design and implement her college English class "in an interactive and interesting manner" (Class-observation-H-1). Again, this EL effort enabled her to align her teaching practice with her educational conception and teaching habitus; this alignment in turn mitigated her disgust towards the exam-oriented English teaching. In other words, she was still hopeful, as a consequence of her effective EL, about holding on to her educational conception, even if her teaching practice in the exam-oriented institutional context was not in complete accordance with the former two.

In addition, Ms. H. also felt hopeful about her professional development. Faced with similar obstacles and frustrations that other veteran lecturers like Mr. M. encountered, her emotions of shame, uncertainty, and non-confidence were reduced to a large extent via effective EL. Thanks to the advice and encouragement of her supervisor, whom she "always respected and trusted as an idol", she successfully managed to overcome her fear to carry out research, and persuaded herself, through deep acting EL, to "invest more time in academic research that is more valued than teaching achievements" (Interview-H-3). In addition, she actively "participated in in-service trainings on academic writing and research application", "turned to experienced colleagues and friends on feasible research methods and proper research themes", and gradually "found more confidence and sense of achievement" (Interview-H-4). In other words, her deep acting EL in the form of action, 
again, negotiated the tension between her research practice and the emotion rules for college English teachers as academic scholars. Over time, she gradually eliminated her helplessness with respect to challenging research work, which better prepared her for professional title promotion, which in turn facilitated the sustainability of her professional development.

The narratives of Mr. M. and Ms. H. reveal not only their different EL efforts based on similar emotion rules in the context of Chinese higher education, their specific educational conception, and professional practice, but also the different effects of their EL on their divergent professional developmental paths, which will be further discussed in the following section.

\section{Discussion}

Our findings are in line with observations by Her and De Costa [57], Benesch [39], and Miller and Gkonou [41] that the EL of teachers is interwoven with their teaching, research, and training. As illustrated in our findings, these aspect of the professional lives of Mr. M. and Ms. H. constituted the core of their English teaching and professional identities from the very start point of their careers. We also agree with previous researchers that teachers' personal and professional development had been always accompanied with the historicity of their emotions [37] and their EL [26]. However, our longitudinal study further emphasized that teacher EL was shaped and reshaped by the ups and downs of their personal history, interactions with students and colleagues, changes to administrative and institutional policies, as well as the dynamic educational, historical, and cultural contexts.

As illustrated in our findings, profound changes or influential crises often took place at turning points, but teachers' EL experiences may lead to different results because of their divergent educational conception, and therefore different professional development. In our study, EL strategy in the form of action, when handling job crises, contrastively hindered Mr. M.'s motivation and facilitated Ms. H.'s drive in her personal and professional growth Naturally, it is not hard to imagine many following turning points in their professional lives, when they repeated or adjusted their strategies of EL according to the encouraging or discouraging results of their previous EL experiences, which eventually exhibited spiral elements (a downward, negative spiral in Mr. M.'s case and an upward, positive spiral in Ms. H.'s case) of their EL. In that respect, our findings are consistent with Lavy and Eshet's [51] observation about the negative spiral effects of teachers' negative emotions and surface acting (Mr. M.), and the positive spiral of their positive emotions and decreased surface acting (Ms. H.). Specifically, Ms. H.'s EL successful efforts as mediated in virtuous spiral circles aroused and maintained more positive emotions, which in turn elevated and advanced her through a promising and sustainable professional development in ways that aligned with what Yang, Shu, and Yin [58] described as incremental developmental phases that include progressing from surviving to striving, and thriving, career stages. In the case of Mr. M., his EL devolved into a vicious and negative spiral circle, which was characterized by accumulated negative emotions and little positive emotions towards his career. Such a downward spiral eventually dragged him to emotional exhaustion, and thus harmed his occupational well-being, a tragic consequence similar to what Taxer and Frenzel [18] warned against in their work.

In this sense, our findings are also in agreement with the findings of previous studies that have reported that surface acting is positively related to job burnout [23,59-61] and negatively correlated to teachers' efficacy [25,47]. In addition, we further found that the surface acting of long-term depression is less likely to solve deeply rooted problems; if anything, they are more likely to trigger negative emotions, which only lead to a destructive influence on teacher well-being and impede their professional development. Mr. M. is a typical case in point. In contrast to what Taylor, Newberry, and Clark [49] found that once teachers better understand their surface acting and their deeper emotions felt, they will carry out more effective EL and experience less negative emotions overall, we found that Mr. M.'s case was the direct opposite. He originally preferred an EL strategy of genuine expression of negative emotions to his students through direct criticism-at the start of his 
career-in order to maintain alignment between his educational conception and professional practice. However, when crucial inflection points emerged, which stemmed from a lack of institutional support, a history of a series of seemingly punitive educational reforms, and the current exam-oriented accountability culture in college English courses [43], Mr. M. became increasingly disappointed, anxious, angry, and helpless. Unfortunately, he failed to manage these deeper emotions through enacting effective EL strategies, and he gradually retreated to surface acting of feigned indifference. In the long term, ineffective long-term surface acting actually led to more intense emotional conflicts and EL struggles for him, until he lapsed into emotional exhaustion and ultimately ended his career as a teacher.

Lastly, EL in action, especially when accompanied by deep acting and genuine expression of emotions, can potentially play a constructive and facilitating role in virtuous spiral circles of EL formation that ultimately help sustain teacher development. This was well demonstrated by the case of Ms. H., who frequently relied on the EL strategy of genuine expression of positive emotions to her students to cultivate active and trustful teacher-student interactions, and on genuine expression of negative emotions towards the administrators in her university to deliver candid and persuasive negotiation with her superiors. In addition, she conducted an EL strategy of deep acting when she faced a professional bottleneck, such as meeting mandatory teaching hour requirements and the demand for academic research in teacher evaluation. By addressing head-on the irreversible trend of curricular reforms at both her university and within the wider national higher education landscape, she illustrated the need to strategically comply with national and institutional policies, while also creating opportunities for herself to enact some degree of professional agency. In fact, the core of her EL efforts was her agentive actions that included her active interactions with students, brave negotiation with the administration, and her commitment to academic research. Ms. H.'s EL in action was essential to ensure the effectiveness and virtuous circle of her EL efforts, which subsequently enabled her to secure sustainable professional development.

\section{Conclusions}

In conclusion, our participants, as veteran college English lecturers, had mixed emotions and pervasive EL throughout their professional development experience, and their EL habitus was shaped and reshaped by their life history in personal, relational, institutional, and sociohistorical contexts. Additionally, our longitudinal study confirmed that their previous experiences of EL influenced their present EL practice, which in turn tended to predict their future EL preferences. In addition, our findings revealed that effective EL effort, especially in the form of actions combined with deep acting and genuine expression, was critical to the virtuous circle of EL and sustainable professional development of our participant teachers. By contrast, ineffective EL effort, particularly the long-term surface enactment of negative emotions (without eradicating the root causes or changing the unfavorable conditions) can impede the long-term sustainability of teacher development. Based on these findings, we conceptualize teachers' EL as a contextual and dynamic process that takes the form of spiral circles that teachers encounter throughout their professional life. These spiral circles can be virtuous or vicious in nature, and can thus either facilitate or undermine, respectively, the sustainability of their professional development.

The implications of our research are twofold. On the one hand, college English teachers and teachers in general should be encouraged to understand the history of their emotions and EL habitus, a diachronic perspective rather than static and labeled viewpoint, so that they can timely recognize and resolve the roots of long-range challenges in their professional life, and deliberately promote the effectiveness of their EL, with an ultimate purpose of facilitating sustainable teacher development. On the other hand, administrators, policy makers, and reform advocates in education should be more sensitive to the manifestations of teachers' dynamic emotions and EL struggles to provide targeted support to teachers and hopefully reduce the resistance of teachers to the enactment of educational policies and reforms. 
One obvious limitation of our work is the lack of the student comments about Mr. M., which should have served as a means of direct evidence and contributed towards data triangulation. However, in the high-context culture of China, messages are not always necessarily delivered in explicit words. Instead, most of the information is already in the context, and even silence conveys meanings regarding relationships. In the case of Mr. M., the fact that his students refused to offer any comments, or the silence of his students, spoke loudly of the distance and lack of trust in the teacher-student relationship, which eventually helped us analyze and interpret his other data. Consequently, we hereby propose to our peer researchers to pay due attention to nonverbal information in research data, which may reveal interesting findings. Another limitation is that our focal teachers taught college English in the same city in China, which means we did not explore the regional and disciplinary differences with respect to the historicity of teachers' EL, which may also exert some influence on the sustainability of teacher development. Thus, we suggest that teacher studies in the future engage with cross-regional and interdisciplinary participants to further explore elements across institutional, regional, and national contexts, as they focus on the interaction between teachers' EL changes and the sustainability of their professional development.

Author Contributions: Conceptualization, X.D., P.I.D.C. and G.T.; methodology, X.D. and P.I.D.C.; validation, X.D.; formal analysis, X.D. and P.I.D.C.; investigation, resources, and data curation, X.D.; writing - original draft preparation, X.D.; writing—review and editing, P.I.D.C. and G.T.; supervision, G.T.; funding acquisition, X.D. All authors have read and agreed to the published version of the manuscript.

Funding: This research was funded by the Beijing Science and Technology University, grant numbers 2020GJZD03 and 2021YJPY232, and Beijing Association of Higher Education, grant number YB2021133.

Institutional Review Board Statement: Ethical review and approval were waived for this study, due to the unavailability of the Institutional Review Board (or Ethics Committee) at the affiliation of the first author who was responsible for data collection.

Informed Consent Statement: Informed consent was obtained from all subjects involved in the study.

Data Availability Statement: The data presented in this study are available on request from the corresponding author.

Acknowledgments: We sincerely appreciate the valuable contribution of our focal teachers who opened up not only their class but also themselves to the first author, Ding.

Conflicts of Interest: The authors declare no conflict of interest. The funders had no role in the design of the study; in the collection, analyses, or interpretation of data; in the writing of the manuscript, or in the decision to publish the results.

\section{Appendix A Interview Outline}

1. The first interview:

(1) Would you please describe your job-hunting experiences before your teaching career? Who or what events influenced your decision to be a college English teacher?

(2) Before you gave the first class to your students at the beginning of your teaching career, what did you expect in terms of what kind of teacher you would like to be, how to teach college English well, what your students were like, how your university would develop, etc.?

(3) How do you like your career now as a college English teacher? Are there any differences from your original expectations? Who or what events led to these differences?

(4) Would you please describe your current professional life, particularly your teaching? What about your interaction and relationship with people around, 
such as your students and colleagues? What do you think of your professional development so far?

2. Interviews after class observations:

(1) Just now I noticed in your class that ..., would you please tell me why did you say / act like that? How did you feel at that time? Why?

(2) In today's class, did anything out of your expectation take place? If yes, how did you feel at that time? Why?

(3) In today's class, did anything impress you? Why? Any impacts or consequences?

(4) Would you please tell me some unforgettable stories in your class recently? How did you feel at that time? Why?

3. Additional questions in the last interview:

(1) Are you going to make any changes in your teaching next semester or in the near future? Why?

(2) Do you have any plan for your professional development within 5 years? Why?

\section{References}

1. Sutton, R.E.; Wheatley, K.F. Teachers' Emotions and Teaching: A Review of the Literature and Directions for Future Research. Educ. Psychol. Rev. 2003, 15, 327-358. [CrossRef]

2. Van Veen, K.; Sleegers, P. Teachers' Emotions in a Context of Reforms: To a Deeper Understanding of Teachers and Reforms. In Advances in Teacher Emotion Research; Schutz, P.A., Zembylas, M., Eds.; Springer: Boston, MA, USA, 2009; pp. 233-251.

3. Benesch, S. Considering Emotions in Critical English Language Teaching: Theories and Praxis; Routledge: New York, NY, USA, 2012; ISBN 978-0-415-88203-3.

4. Cowie, N. Emotions That Experienced English as a Foreign Language (EFL) Teachers Feel about Their Students, Their Colleagues and Their Work. Teach. Teach. Educ. 2011, 27, 235-242. [CrossRef]

5. Cross, D.I.; Hong, J.Y. An Ecological Examination of Teachers' Emotions in the School Context. Teach. Teach. Educ. 2012, 28, 957-967. [CrossRef]

6. Day, C.; Harris, B. Understanding and Planning Emotions Research. In Methodological Advances in Research on Emotion and Education; Zembylas, M., Schutz, P.A., Eds.; Springer: New York, NY, USA; London, UK, 2016; pp. 55-67; ISBN 978-3-319-29047-8.

7. Fried, L.; Fried, C.; Dobozy, E. Teacher Emotion Research: Introducing a Conceptual Model to Guide Future Research. Issues Educ. Res. 2015, 25, 415-441.

8. Golombek, P.; Doran, M. Unifying Cognition, Emotion, and Activity in Language Teacher Professional Development. Teach. Teach. Educ. 2014, 39, 102-111. [CrossRef]

9. Hargreaves, A. The Emotional Practice of Teaching. Teach. Teach. Educ. 1998, 14, 835-854. [CrossRef]

10. Hargreaves, A. Mixed Emotions: Teachers' Perceptions of Their Interactions with Students. Teach. Teach. Educ. 2000, 16, 811-826. [CrossRef]

11. Hargreaves, A. Educational Change Takes Ages: Life, Career and Generational Factors in Teachers' Emotional Responses to Educational Change. Teach. Teach. Educ. 2005, 21, 967-983. [CrossRef]

12. Jeffrey, B.; Woods, P. Feeling Deprofessionalised: The Social Construction of Emotions during an OFSTED Inspection. Camb. J. Educ. 1996, 26, 325-343. [CrossRef]

13. Martínez Agudo, J.d.D. (Ed.) Emotions in Second Language Teaching: Theory, Research and Teacher Education, 1st ed.; Springer: Cham, Switzerland, 2018; ISBN 978-3-319-75438-3.

14. Nias, J. Primary Teachers Talking: A Study of Teaching as Work; Routledge: London, UK; New York, NY, USA, 1989; ISBN 978-0-415-01115-0.

15. Nias, J. Thinking about Feeling: The Emotions in Teaching. Camb. J. Educ. 1996, 26, 293-306. [CrossRef]

16. Schutz, P.A. Inquiry on Teachers' Emotion. Educ. Psychol. 2014, 49, 1-12. [CrossRef]

17. Schutz, P.A.; Zembylas, M. (Eds.) Advances in Teacher Emotion Research: The Impact on Teachers' Lives; Springer: Boston, MA, USA, 2009; ISBN 978-1-4419-0563-5.

18. Taxer, J.L.; Frenzel, A.C. Inauthentic Expressions of Enthusiasm: Exploring the Cost of Emotional Dissonance in Teachers. Learn. Instr. 2018, 53, 74-88. [CrossRef]

19. van Veen, K.; Lasky, S. Emotions as a Lens to Explore Teacher Identity and Change: Different Theoretical Approaches. Teach. Teach. Educ. 2005, 21, 895-898. [CrossRef]

20. $\mathrm{Xu}, \mathrm{Y}$. Language Teacher Emotion in Relationships: A Multiple Case Study. In Preparing Teachers for the 21st Century; Zhu, X., Zeichner, K., Eds.; New Frontiers of Educational Research; Springer: Berlin/Heidelberg, Germany, 2013; pp. 371-393; ISBN 978-3-642-36969-8.

21. Yin, H. Knife-like Mouth and Tofu-like Heart: Emotion Regulation by Chinese Teachers in Classroom Teaching. Soc. Psychol. Educ. 2016, 19, 1-22. [CrossRef] 
22. Zembylas, M. Investigating the Emotional Geographies of Exclusion at a Multicultural School. Emot. Space Soc. 2011, 4, 151-159. [CrossRef]

23. Zhang, Q.; Zhu, W. Exploring Emotion in Teaching: Emotional Labor, Burnout, and Satisfaction in Chinese Higher Education. Commun. Educ. 2008, 57, 105-122. [CrossRef]

24. Isenbarger, L.; Zembylas, M. The Emotional Labour of Caring in Teaching. Teach. Teach. Educ. 2006, 22, 120-134. [CrossRef]

25. Yin, H.; Huang, S.; Lee, J.C.K. Choose Your Strategy Wisely: Examining the Relationships between Emotional Labor in Teaching and Teacher Efficacy in Hong Kong Primary Schools. Teach. Teach. Educ. 2017, 66, 127-136. [CrossRef]

26. Ding, X. Emotional labor of English teachers: A review of research at home and abroad. Foreign Lang. Educ. China 2021, 4, 3-8.

27. Hochschild, A.R. The Managed Heart: Commercialization of Human Feeling, 1st ed.; University of California Press: Berkeley, CA, USA, 1983.

28. Ashforth, B.E.; Humphrey, R.H. Emotional Labor in Service Roles: The Influence of Identity. Acad. Manag. Rev. 1993, 18, 88-115. [CrossRef]

29. Burić, I.; Penezić, Z.; Sorić, I. Regulating Emotions in the Teacher's Workplace: Development and Initial Validation of the Teacher Emotion-Regulation Scale. Int. J. Stress Manag. 2017, 24, 217-246. [CrossRef]

30. Yin, H. The Effect of Teachers' Emotional Labour on Teaching Satisfaction: Moderation of Emotional Intelligence. Teach. Teach. 2015, 21, 789-810. [CrossRef]

31. Yin, H.; Lee, J.C.K.; Zhang, Z.; Jin, Y. Exploring the Relationship among Teachers' Emotional Intelligence, Emotional Labor Strategies and Teaching Satisfaction. Teach. Teach. Educ. 2013, 35, 137-145. [CrossRef]

32. Zembylas, M. Constructing Genealogies of Teachers' Emotions in Science Teaching. J. Res. Sci. Teach. 2002, 39, 79-103. [CrossRef]

33. Turner, J.H. On the Origins of Human Emotions: A Sociological Inquiry into the Evolution of Human Affect; Stanford University Press: Stanford, CA, USA, 2000; ISBN 978-0-8047-3719-7.

34. Oatley, K.; Johnson-Laird, P.N. Cognitive Approaches to Emotions. Trends Cogn. Sci. 2014, 18, 134-140. [CrossRef] [PubMed]

35. Vaughn, L.M. Psychology and Culture: Thinking, Feeling, and Behaving in a Global Context, 2nd ed.; Routledge: London, UK; Taylor \& Francis Group: New York, NY, USA, 2019; ISBN 978-1-138-57680-3.

36. Turner, J.H.; Stets, J.E. The Sociology of Emotions; Cambridge University Press: Cambridge, UK; New York, NY, USA, 2005; ISBN 978-0-521-84745-2.

37. Zembylas, M. Teaching with Emotion: A Postmodern Enactment; Information Age Publishing: Greenwich, CT, USA, 2005; ISBN 978-1-59311-328-5.

38. Yin, H. Teacher emotion: An issue urgently to be taken into consideration. Res. Educ. Dev. 2007, 3B, 44-48. (In Chinese) [CrossRef]

39. Benesch, S. Emotions and English Language Teaching: Exploring Teachers' Emotion Labor; Routledge: New York, NY, USA, 2017; ISBN 978-1-138-83213-8.

40. Hochschild, A.R. The Managed Heart: Commercialization of Human Feeling (Reprint Edition); University of California Press: Berkeley, CA, USA, 2012; ISBN 978-0-520-27294-1.

41. Miller, E.R.; Gkonou, C. Language Teacher Agency, Emotion Labor and Emotional Rewards in Tertiary-Level English Language Programs. System 2018, 79, 49-59. [CrossRef]

42. Yin, H. Teachers' Emotional Labor in Their Professional Practice. Res. Educ. Dev. 2009, 10, 18-22. (In Chinese) [CrossRef]

43. Ding, X. Teachers' Emotion Labor: A Multiple Case Study of Longtime College English Lecturers. Ph.D. Thesis, Beijing Foreign Studies University, Beijing, China, 2019.

44. Gross, J.J. The Emerging Field of Emotion Regulation: An Integrative Review. Rev. Gen. Psychol. 1998, 2, 271-299. [CrossRef]

45. Gross, J.J. Emotion Regulation in Adulthood: Timing Is Everything. Curr. Dir. Psychol. Sci. 2001, 10, 214-219. [CrossRef]

46. Yin, H. Adaptation and Validation of the Teacher Emotional Labour Strategy Scale in China. Educ. Psychol. 2012, 32, 451-465. [CrossRef]

47. Zheng, X.; Yin, H.; Wang, M. Leading with Teachers' Emotional Labour: Relationships between Leadership Practices, Emotional Labour Strategies and Efficacy in China. Teach. Teach. 2018, 24, 965-979. [CrossRef]

48. Sutton, R.E. Emotional Regulation Goals and Strategies of Teachers. Soc. Psychol. Educ. 2004, 7, 379-398. [CrossRef]

49. Taylor, L.P.; Newberry, M.; Clark, S.K. Patterns and Progression of Emotion Experiences and Regulation in the Classroom. Teach. Teach. Educ. 2020, 93, 103081. [CrossRef]

50. Gao, Y.; Cui, Y. Tracking English teachers emotional labor changes in an educational reform: A qualitative case study. Foreign Lang. Educ. China 2021, 4, 9-17.

51. Lavy, S.; Eshet, R. Spiral Effects of Teachers' Emotions and Emotion Regulation Strategies: Evidence from a Daily Diary Study. Teach. Teach. Educ. 2018, 73, 151-161. [CrossRef]

52. Dörnyei, Z. Research Methods in Applied Linguistics: Quantitative, Qualitative, and Mixed Methodologies; Oxford applied linguistics; Oxford University Press: Oxford, UK; New York, NY, USA, 2007; ISBN 978-0-19-442258-1.

53. Patton, M.Q. Qualitative Evaluation and Research Methods, 2nd ed.; Sage Publications: Newbury Park, CA, USA, 1990; ISBN 978-0-8039-3779-6.

54. Bogdan, R.; Biklen, S.K. Qualitative Research for Education: An Introduction to Theory and Methods, 3rd ed.; Allyn and Bacon: Boston, MA, USA, 1998; ISBN 978-0-205-27564-9.

55. Gkonou, C.; Miller, E.R. An Exploration of Language Teacher Reflection, Emotion Labor, and Emotional Capital. TESOL J. 2021, 55, 134-155. [CrossRef] 
56. Zembylas, M. Caring for Teacher Emotion: Reflections on Teacher Self-Development. Stud. Philos. Educ. 2003, 22, 103-125. [CrossRef]

57. Her, L.; De Costa, P.I. When Language Teacher Emotions and Language Policy Intersect: A Critical Perspective. System 2022, 105, 102745. [CrossRef]

58. Yang, S.; Shu, D.; Yin, H. 'Frustration Drives Me to Grow': Unraveling EFL Teachers' Emotional Trajectory Interacting with Identity Development. Teach. Teach. Educ. 2021, 105, 103420. [CrossRef]

59. Brotheridge, C.M.; Grandey, A.A. Emotional Labor and Burnout: Comparing Two Perspectives of "People Work". J. Vocat. Behav. 2002, 60, 17-39. [CrossRef]

60. Chang, M.-L. An Appraisal Perspective of Teacher Burnout: Examining the Emotional Work of Teachers. Educ. Psychol. Rev 2009, 21, 193-218. [CrossRef]

61. Tiwari, A.; Saraff, S.; Nair, R. Impact of Emotional Labor on Burnout and Subjective Well-Being of Female Counselors and Female Teachers. J. Psychosoc. Res. 2020, 15, 523-532. [CrossRef] 